\title{
Pengenalan Angka Tulisan Tangan Menggunakan Diagonal Feature Extraction dan Klasifikasi Artificial Neural Network Multilayer Perceptron
}

\author{
M. Ardi Firmansyah ${ }^{\# 1}$, Kurniawan Nur Ramadhani ${ }^{\# 2}$, Anditya Arifianto ${ }^{\# 3}$ \\ \# Laboratorium Multimedia, Fakultas Informatika, Universitas Telkom \\ Jl. Telekomunikasi No. 01, Terusan Buah Batu, Bandung 40257 \\ 1 ardifirmansyah@student.telkomuniversity.ac.id \\ ${ }^{2}$ kurniawannr@telkomuniversity.ac.id \\ 3 anditya@telkomuniversity.ac.id
}

\section{Abstract}

In this research, we built a numerical handwriting recognition system using Diagonal Feature Extraction method and Artificial Neural Network Multilayer Perceptron. Diagonal Feature Extraction divided the image into several areas. In each area, the method calculated the average pixel value on each diagonal to obtain the feature values of the area. The diagonal features were combined with the horizontal and vertical mean values in the matrix of the area to enrich the information of the image. This method achieved accuracy of $92.80 \%$ at the test stage using $1000 \mathrm{Cl}$ datasets and $92.60 \%$ at the test stage using 1000 MNIST datasets. The combination of diagonal and horizontal averages produced the highest accuracy in recognizing handwriting numbers.

Keywords: Handwriting recognition, Diagonal based feature, Multilayer perceptron, backpropagation.

\begin{abstract}
Abstrak
Pada penelitian ini dibangun sistem pengenalan angka tulisan tangan menggunakan metode ekstraksi ciri diagonal dan Artificial Neural Network Multilayer Perceptron. Pada ekstraksi ciri diagonal, citra dibagi menjadi beberapa area yang sama besar. Pada tiap area dihitung rata-rata nilai piksel pada setiap diagonalnya kemudian dirata-ratakan untuk mendapatkan nilai ciri pada area tersebut. Ciri diagonal dikombinasikan dengan nilai rata-rata horizontal dan vertikal pada matriks area tersebut untuk memperkuat informasi pada citra. Metode ini mencapai akurasi sebesar $92.80 \%$ pada tahap pengujian menggunakan 1000 dataset $\mathrm{C} 1$ dan $92.60 \%$ pada tahap pengujian menggunakan 1000 dataset MNIST. Kombinasi fitur diagonal dan rata-rata horizontal menghasilkan akurasi tertinggi dalam mengenali angka tulisan tangan.
\end{abstract}

Kata Kunci: Handwriting recognition, Diagonal based feature, Multilayer perceptron, backpropagation.

\section{Pendahuluan}

Pemilihan Umum (Pemilu) adalah kegiatan yang dilakukan warga negara Indonesia untuk menentukan seorang pemimpin. Pemilu Presiden dan Wakil Presiden (PPWP) yang diadakan pada tahun 2014. Dalam PPWP yang telah diselenggarakan sebelumnya, proses rekapitulasi nasional membutuhkan waktu lebih kurang 3 hari karena proses ini dilakukan manual oleh panitia KPU pusat. Hal ini dapat dipermudah dengan kemampuan komputer yang dapat mengenali angka tulisan tangan pada formulir $\mathrm{C}$, atau yang biasa disebut dengan Handwritten Character Recognition (HCR). HCR hingga saat ini masih memiliki tantangan karena banyaknya variasi dari bentuk tulisan tangan yang akan dikenali.

Bentuk tulisan tangan yang terdapat pada formulir $\mathrm{C} 1$ sangat bervariasi karena formulir $\mathrm{C} 1$ dikumpulkan dari semua Tempat Pemungutan Suara (TPS) di Indonesia. Untuk mengakomodasi besarnya variasi data yang digunakan, dataset yang berasal dari Modified National Institute of Standards and Technology (MNIST) digunakan sebagai data tambahan karena sudah umum digunakan pada kasus pengenalan tulisan tangan [3]. Selain itu, dataset MNIST digunakan juga untuk melakukan evaluasi performansi pada dataset formulir $\mathrm{C} 1$. 
Pada penelitian ini, dibangun sistem pengenalan angka tulisan tangan menggunakan metode ekstraksi ciri Diagonal Based Feature. Metode ini dipilih karena dapat memberikan hasil pengenalan yang baik dibandingkan metode ekstraksi ciri secara Horizontal dan Vertikal [6]. Ciri yang telah didapat menggunakan metode ekstraksi ciri Diagonal Based Feature diklasifikasikan menggunakan metode Artificial Neural Network Multilayer Perceptron yang biasa digunakan dalam bidang pengenalan pola [1].

\section{DASAR TEORI}

\section{A. Diagonal Based Feature Extraction}

Diagonal Based Feature adalah salah satu metode ekstraksi ciri yang dapat digunakan mendapatkan ciri karakter tulisan tangan. Metode tersebut telah diuji pada beberapa karakter tulisan tangan seperti karakter Gurumukhi yang mendapatkan akurasi sebesar 95.74\% [2] dan karakter angka Kannada yang mendapatkan akurasi sebesar 97.80\% [5]. Diagonal Based Feature Extraction dilakukan dengan membagi sebuah citra menjadi beberapa zona sama besar. Pada setiap zona, dilakukan perhitungan ciri titik pada setiap diagonalnya [4].

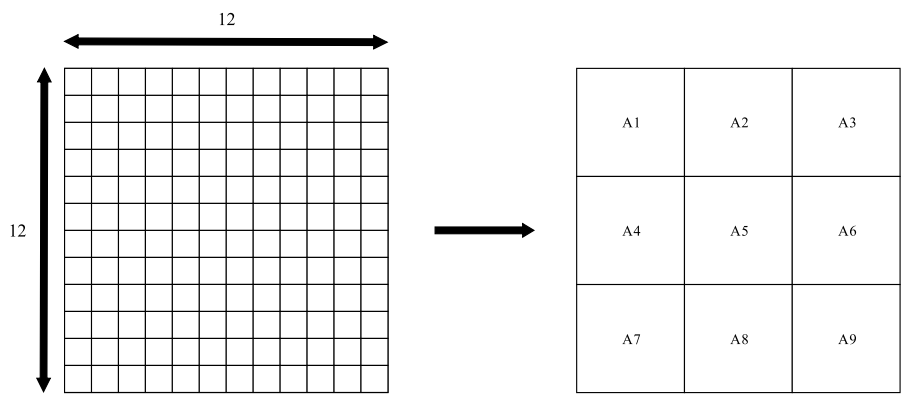

Gambar 1 - Contoh pembagian area pada citra

Contohnya pada citra yang berukuran $12 \times 12$ piksel, dibagi menjadi 9 area sama besar. Sehingga pada setiap areanya berukuran $4 \times 4$ piksel seperti pada Gambar 1 .

Untuk setiap area, jumlah piksel yang ada pada setiap diagonal kemudian dirata-ratakan untuk mendapatkan sebuah sub-feature dari citra tersebut. Sehingga sub-feature yang ada pada setiap area berjumlah 9 sesuai dengan jumlah area yang ada.

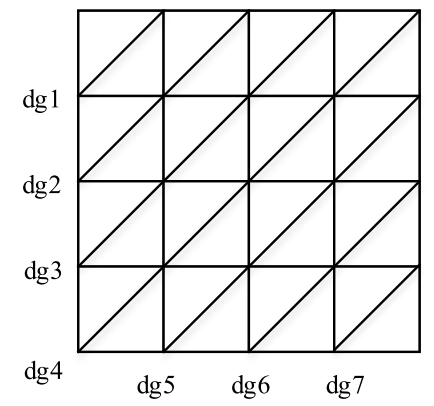

Gambar 2 - Contoh perhitungan diagonal pada area berukuran $4 \times 4$

Sehingga, pada area yang berukuran $\mathrm{n} \times \mathrm{n}$ dapat dihitung nilai sub-feature dari area tersebut dengan persamaan berikut. 


$$
\text { SubFeature }(\text { Area })=\frac{1}{2 n-1} \sum_{i=1}^{2 n-1} d g_{i}
$$

\section{B. Artificial Neural Network - Multilayer Perceptron}

Artificial Neural Network - Multilayer Perceptron (ANN-MLP) adalah jaringan syaraf tiruan dengan algoritma pembelajaran supervised. MLP terdiri dari beberapa lapis neuron. Setiap neuron pada suatu lapisan saling terhubung dengan semua neuron pada lapisan setelahnya. Neuron pada lapisan input merepresentasikan data masukan untuk setiap dimensinya [7].

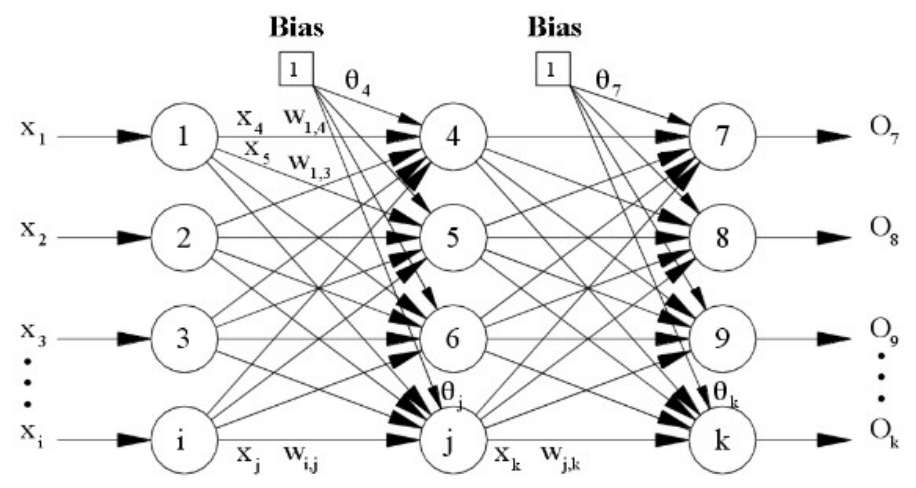

Gambar 3 - Contoh arsitektur MLP dengan 1 hidden layer

Pada Gambar 3 sinyal input $\left(x_{1}, x_{2}, x_{3}, \ldots, x_{i}\right)$ masuk ke dalam neuron $\mathrm{j}$ pada hidden layer (tengah) melalui bobot masing-masing $\left(w_{1, j}, w_{2, j}, w_{3, j}, \ldots, w_{i, j}\right)$, kemudian dilakukan penjumlahan. Contoh untuk neuron 4 , sinyal input dengan panjang dimensi $m$ dihitung dengan persamaan:

$$
V=\sum_{i=1}^{m} x_{i} \times w_{i, 4}
$$

Kemudian, output dari neuron 4 dihitung dengan salah satu fungsi aktivasi seperti fungsi sigmoid yang dinotasikan dengan $A_{4}(V)$.

$$
A_{4}(V)=\frac{1}{1+e^{-V}}
$$

Fungsi aktivasi sigmoid yang menerima masukan $V$ akan menghasilkan grafik fungsi yang bersifat nonlinear seperti yang digambarkan pada Gambar 4. 


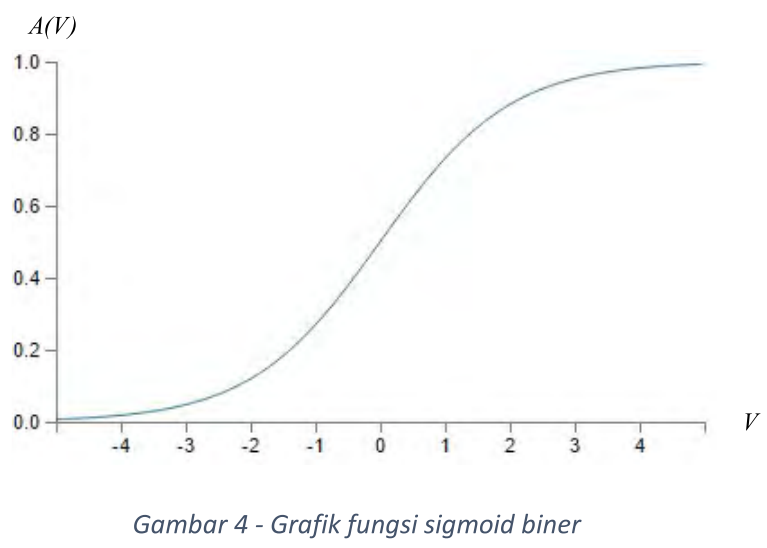

Jika dilihat pada Gambar 4, grafik fungsi aktivasi pada nilai masukan $V$ diantara -2 hingga 2 sangat curam. Hal ini berarti perubahan kecil pada nilai $V$ mengakibatkan perubahan yang signifikan terhadap keluaran fungsi sigmoid sehingga dengan menggunakan fungsi aktivasi sigmoid, aktivasi neuron pada Artificial Neural Network berjalan dengan baik.

Ada beberapa macam fungsi aktivasi yang bisa digunakan pada Artificial Neural Network, beberapa diantaranya adalah: Hard Limit, Threshold, Identitas, Symetric Hard Limit, Radial Basis Function, TanH yang merupakan perluasan dari sigmoid, serta Softmax yang bertujuan untuk memaksimalkan nilai aktivasi terhadap 1 neuron dari banyak neuron yang ada.

Proses yang terjadi pada Multilayer Perceptron dengan algoritma pembelajaran backpropagation terbagi menjadi dua, feedforward dan backpropagation. Pada proses feedforward, data masukan dirambatkan ke dalam jaringan lapisan demi lapisan hingga mencapai lapisan keluaran dan menghasilkan nilai keluaran pada setiap node. Selanjutnya nilai keluaran pada setiap node dibandingkan dengan nilai yang sebenarnya dan dihitung besarnya tingkat galat (error) yang dihasilkan. Dengan nilai error yang dihasilkan oleh proses feedforward, proses backpropagation mengubah nilai bobot $w$ agar galat (error) yang dihasilkan pada proses feedforward selanjutnya semakin mengecil [7]. Hal ini dilakukan secara terus menerus hingga beberapa siklus (epoch) untuk mendapatkan nilai bobot yang optimal.

\section{PERANCANGAN SISTEM}

Sistem pengenalan angka tulisan tangan akan dilakukan dalam 3 tahap utama yang dilakukan secara berurutan, yaitu tahap preprocessing citra, tahap ekstraksi ciri diagonal pada setiap citra, dan tahap klasifikasi menggunakan Neural Network. Proses ini secara umum digambarkan pada diagram alir berikut. 


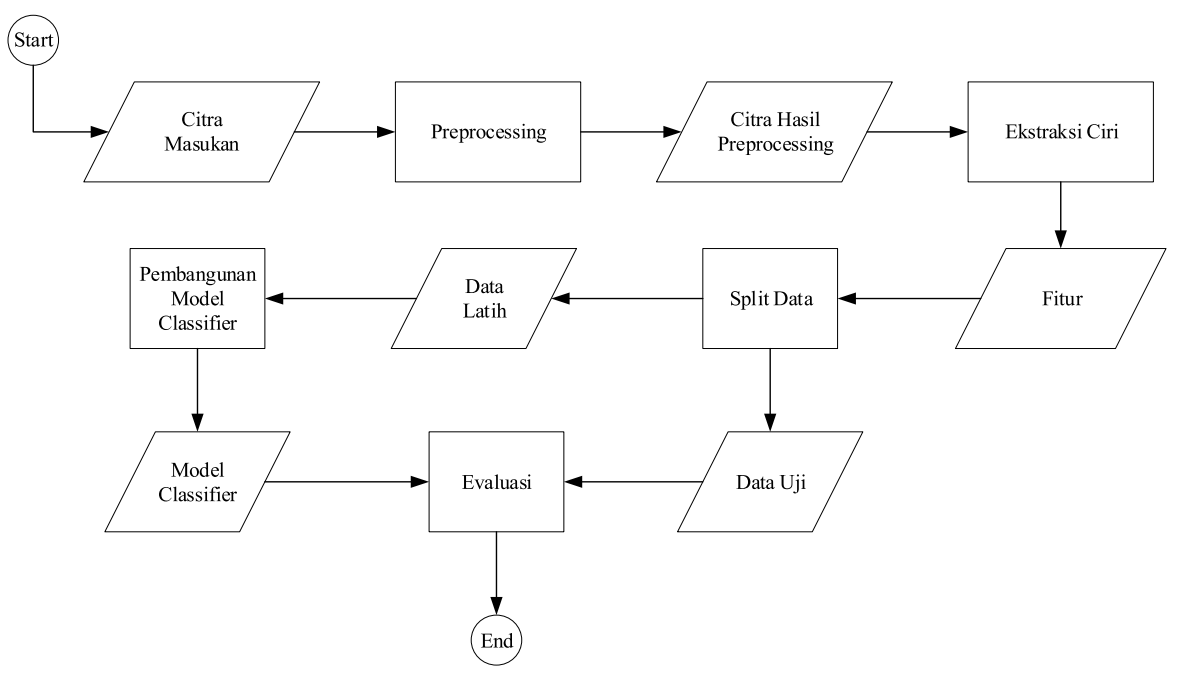

Gambar 5 - Diagram alir gambaran umum sistem

Sebelum memasuki tahap preprocessing, data citra angka tulisan tangan dikumpulkan terlebih dahulu. Setelah data citra terkumpul, pada tahap preprocessing citra diolah hingga menghasilkan citra yang sesuai untuk masukan ektraksi ciri, yaitu citra biner yang telah ditipiskan garisnya (thinning) yang membentuk kerangka angka tulisan tangan. Setelah itu, ekstraksi ciri dilakukan dan menghasilkan vektor ciri diagonal untuk setiap data citra. Dari vektor ciri diagonal didapat, keseluruhan data dibagi menjadi 2 bagian data yaitu data latih dan data uji. Data latih digunakan untuk membangun model klasifikasi yang diuji bersama data uji.

\section{HASIl PENGUJIAN DAN ANALISIS}

\section{A. Pengujian Ekstraksi Ciri Diagonal}

Pada skenario pengujian ini terdapat dua parameter pengujian, yaitu ukuran pembagian area pada citra dan kombinasi fitur diagonal terhadap penambahan fitur rata-rata horizontal dan vertikal. Pengujian terhadap kedua parameter tersebut dilakukan untuk mendapatkan kombinasi fitur yang optimal yang akan dilatih dan diuji pada Artificial Neural Network Multilayer Perceptron.

Pengujian terhadap ukuran pembagian area pada citra dilakukan pada ukuran area sebagai berikut.

- $5 \times 5$ dengan jumlah fitur sebanyak 256 ,

- $8 \times 8$ dengan jumlah fitur sebanyak 100 ,

- $10 \times 10$ dengan jumlah fitur sebanyak 64,

- dan $16 \times 16$ dengan jumlah fitur sebanyak 25 .

Area-area tersebut akan dikombinasikan dengan kombinasi fitur diagonal, rata-rata fitur secara horizontal, serta rata-rata fitur secara vertikal. Jumlah fitur pada setiap kombinasi dapat dilihat pada Tabel 1. 
Table 1 - Jumlah Fitur pada setiap kombinasi ekstraksi ciri

\begin{tabular}{|c||c|c|c|c|}
\hline \multicolumn{1}{|c||}{\multirow{2}{*}{ Area }} & \multicolumn{3}{c|}{ Fitur yang digunakan } \\
\cline { 2 - 5 } & D & DH & DV & DHV \\
\hline \hline $\mathbf{5} \times \mathbf{5}$ & 256 & 272 & 272 & 288 \\
\hline $\mathbf{8} \times \mathbf{8}$ & 100 & 110 & 110 & 120 \\
\hline $\mathbf{1 0} \times \mathbf{1 0}$ & 64 & 72 & 72 & 80 \\
\hline $\mathbf{1 6} \times \mathbf{1 6}$ & 25 & 30 & 30 & 35 \\
\hline
\end{tabular}

Hasil yang didapat dari pengujian ini adalah rata-rata akurasi pada tahap validasi yang dapat dilihat pada Gambar 6.

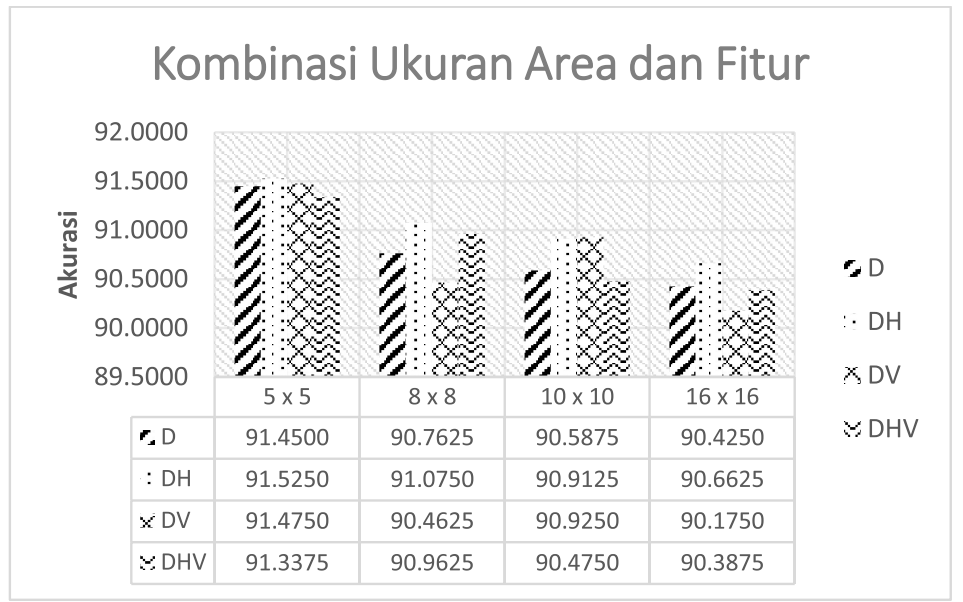

Gambar 6 - Akurasi pada setiap kombinasi parameter ekstraksi ciri

Dari gambar 6, kombinasi ukuran area $5 \times 5$ dan fitur diagonal-horizontal (DH) dapat menghasilkan nilai akurasi lebih tinggi dibanding kombinasi yang lain. Hal ini disebabkan karena pada ukuran area yang lebih besar, piksel 0 (area hitam) yang terlibat pada area tersebut semakin banyak dan piksel 1 yang didapat pada area tersebut semakin sedikit, sehingga kualitas fitur yang didapatkan semakin rendah dan akurasi semakin menurun.

Selain itu, dengan jumlah fitur yang sama fitur diagonal-horizontal menghasilkan tingkat akurasi lebih tinggi dibandingkan dengan diagonal-vertikal pada setiap ukuran area yang diujikan. Hal ini dikarenakan nilai piksel pada bentuk angka pada umumnya lebih bervariasi secara horizontal dibanding secara vertikal.

\section{B. Pengujian Parameter ANN-MLP}

Pada pengujian ini, parameter $A N N-M L P$ yang akan diujikan adalah jumlah hidden neuron dan nilai learning rate yang digunakan pada model klasifikasi yang dibangun. Pengujian ini dilakukan menggunakan fitur dengan ukuran area $5 \times 5$ dan kombinasi fitur diagonal-horizontal (DH) berdasarkan hasil pengujian sebelumnya.

Pada pengujian jumlah hidden neuron, jumlah hidden neuron yang diujikan berada pada rentang 50 
hingga 200 hidden neuron dengan interval sebesar 10 hidden neuron. Pengujian terhadap jumlah hidden neuron dilakukan dengan nilai learning rate sebesar 0.05. Nilai akurasi tertinggi diperoleh dengan jumlah hidden neuron sebesar 160 dengan akurasi sebesar $91.90 \%$. Nilai akurasi lain dapat ditunjukkan pada Gambar 7 .

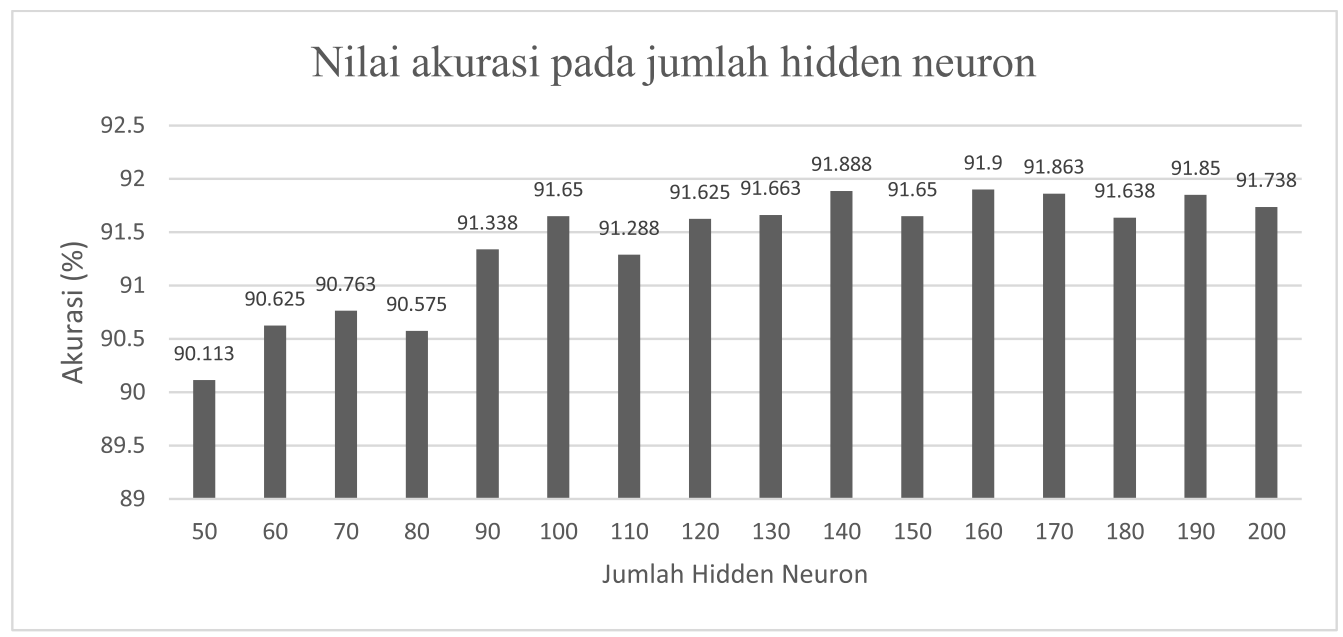

Gambar 7 - Grafik akurasi pengujian jumlah hidden neuron

Selanjutnya dengan 160 hidden neuron, dilakukan pengujian terhadap nilai learning rate. Nilai learning rate yang diujikan adalah 0.01 hingga 0.1 dengan rentang 0.01 . Nilai akurasi yang didapatkan dapat dilihat pada Gambar 8.

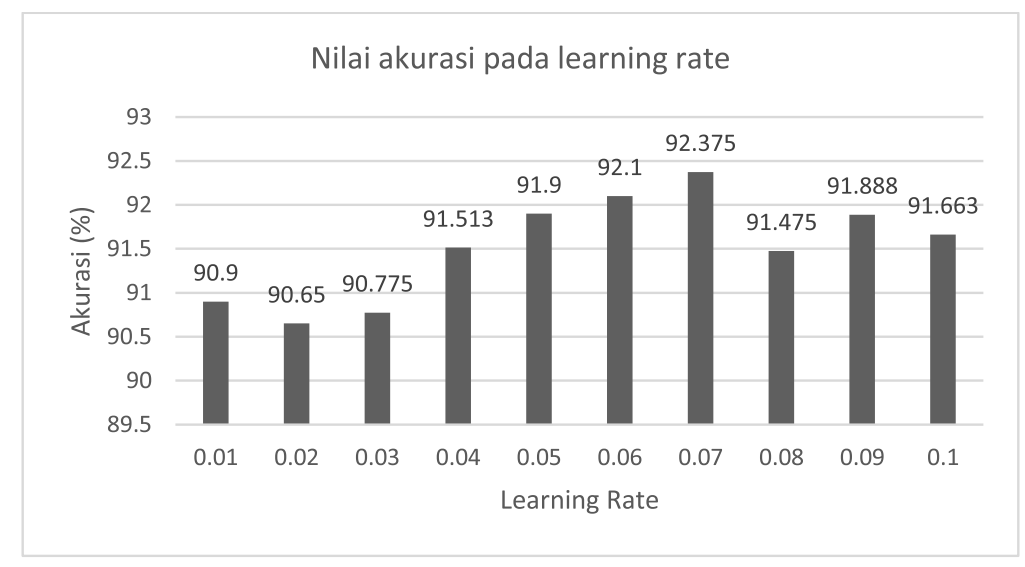

Gambar 8 - Grafik akurasi pengujian nilai learning rate

Nilai akurasi tertinggi diperoleh dengan learning rate sebesar 0.07 dengan akurasi sebesar $92.375 \%$. Nilai akurasi ini menjadi nilai akurasi terbesar dari kombinasi hidden neuron dan learning rate yang diujikan. 


\section{Pengujian terhadap data uji}

Skenario pengujian yang telah dilakukan sebelumnya bertujuan untuk mengetahui parameter yang akan digunakan untuk membangun model klasifikasi Artificial Neural Network Multilayer Perceptron. Dari hasil skenario pengujian yang telah dilakukan, didapatkan hasil bahwa model yang dibangun dengan fitur area $5 \times$ 5 dan kombinasi fitur diagonal-horizontal (DH) dapat menghasilkan akurasi tertinggi dengan jumlah hidden neuron sebanyak 160 dan learning rate sebesar 0.07 pada Artificial Neural Network Multilayer Perceptron.

Pengujian terhadap data uji dilakukan dengan melakukan tahap learning pada seluruh data latih yang berjumlah 8000 data dan diujikan pada 2000 data uji dengan 1000 data C1 dan 1000 data MNIST yang mendapatkan hasil sebagai berikut.

Table 2 - Akurasi pengujian pada data uji

\begin{tabular}{|c|c|c|}
\hline & C1 & MNIST \\
\hline Akurasi & $92.30 \%$ & $92.60 \%$ \\
\hline
\end{tabular}

Selain itu, dari hasil pengujian didapatkan juga confusion matrix untuk uji coba pada kedua dataset seperti yang digambarkan pada Tabel 3.

Table 3 - Confusion matrix pengujian data C1

\begin{tabular}{|c|c|c|c|c|c|c|c|c|c|c|c|}
\hline \multicolumn{12}{|c|}{ Prediksi } \\
\hline & 0 & 1 & 2 & 3 & 4 & 5 & 6 & 7 & 8 & 9 & Error \\
\hline 0 & 107 & 1 & 1 & 0 & 0 & 0 & 2 & 0 & 2 & 0 & 0.053 \\
\hline 1 & 0 & 129 & 0 & 0 & 1 & 0 & 0 & 0 & 0 & 0 & 0.008 \\
\hline 2 & 0 & 4 & 183 & 2 & 0 & 0 & 0 & 2 & 1 & 0 & 0.047 \\
\hline 3 & 0 & 0 & 4 & 106 & 1 & 2 & 0 & 3 & 1 & 2 & 0.109 \\
\hline 4 & 0 & 3 & 0 & 0 & 104 & 0 & 0 & 0 & 0 & 7 & 0.088 \\
\hline 5 & 1 & 1 & 4 & 0 & 0 & 68 & 1 & 0 & 1 & 3 & 0.139 \\
\hline 6 & 0 & 0 & 1 & 2 & 0 & 1 & 66 & 0 & 1 & 0 & 0.070 \\
\hline 7 & 0 & 2 & 0 & 0 & 2 & 0 & 0 & 53 & 0 & 0 & 0.070 \\
\hline 8 & 1 & 0 & 2 & 3 & 0 & 1 & 0 & 0 & 54 & 0 & 0.115 \\
\hline 9 & 0 & 0 & 1 & 3 & 1 & 0 & 1 & 4 & 1 & 53 & 0.172 \\
\hline & & & & Rata & ata $E$ & & & & & & 0.087 \\
\hline
\end{tabular}


Table 4 - Confusion matrix pengujian data MNIST

\begin{tabular}{|c|c|c|c|c|c|c|c|c|c|c|c|}
\hline \multicolumn{11}{|c|}{ Prediksi } & \multirow[b]{2}{*}{ Error } \\
\hline & $\mathbf{0}$ & 1 & 2 & 3 & 4 & 5 & 6 & 7 & 8 & 9 & \\
\hline 0 & 88 & 0 & 0 & 0 & 0 & 1 & 0 & 0 & 1 & 0 & 0.022 \\
\hline 1 & 2 & 116 & 0 & 0 & 0 & 0 & 2 & 1 & 0 & 0 & 0.041 \\
\hline 2 & 0 & 1 & 103 & 2 & 2 & 0 & 0 & 2 & 2 & 0 & 0.080 \\
\hline 3 & 0 & 0 & 0 & 89 & 0 & 1 & 0 & 1 & 1 & 0 & 0.033 \\
\hline 4 & 0 & 1 & 1 & 0 & 76 & 0 & 2 & 0 & 0 & 2 & 0.073 \\
\hline 5 & 0 & 0 & 0 & 3 & 1 & 80 & 0 & 0 & 0 & 0 & 0.048 \\
\hline 6 & 2 & 0 & 1 & 0 & 2 & 1 & 77 & 0 & 1 & 0 & 0.083 \\
\hline 7 & 0 & 5 & 0 & 1 & 2 & 1 & 0 & 91 & 0 & 1 & 0.099 \\
\hline 8 & 2 & 1 & 1 & 6 & 2 & 1 & 0 & 1 & 90 & 1 & 0.143 \\
\hline 9 & 0 & 1 & 0 & 1 & 6 & 2 & 0 & 2 & 1 & 116 & 0.101 \\
\hline \multicolumn{11}{|c|}{ Rata-rata Error } & 0.072 \\
\hline
\end{tabular}

Dari confusion matrix yang didapatkan, dapat dilihat pada dataset $\mathrm{C} 1$ kelas angka yang memiliki nilai error terkecil adalah kelas angka 1 dan kelas angka yang memiliki nilai error terbesar adalah kelas angka 5. Kelas angka 5 pada dataset C1 lebih banyak diklasifikasikan oleh sistem menjadi kelas angka 2 seperti yang terlihat pada gambar 9.

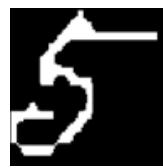

Gambar 9 - Contoh angka 5 yang diprediksi sebagai angka 2

Angka 5 pada gambar 9 memiliki nilai ciri yang mirip dengan angka 2 karena bagian bawah angka 5 yang lebih condong ke bagian kiri citra. Hal ini menyebabkan nilai ciri pada bagian kiri bawah citra lebih besar dan mendekati nilai ciri angka 2.

Pada dataset MNIST, kelas angka yang memiliki nilai error yang terkecil adalah kelas angka 0 dan kelas angka yang memiliki nilai error yang terbesar adalah kelas angka 8. Kelas angka 8 pada dataset MNIST lebih banyak diklasifikasikan oleh sistem menjadi kelas angka 3 seperti yang terlihat pada Gambar 10 .

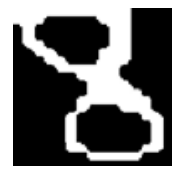

Gambar 10 - Contoh angka 8 yang diprediksi sebagai angka 3

Terlihat pada Gambar 10, angka 8 yang salah diklasifikasikan menjadi angka 3 adalah angka 8 yang memiliki nilai ciri lebih kecil pada area kiri citra. Hal ini dikarenakan bagian bawah angka 8 lebih condong ke arah kanan. Hal ini menyebabkan ciri yang didapatkan pada proses ekstraksi ciri lebih mendekati nilai ciri pada karakter angka 3. 


\section{KESIMPULAN}

Berdasarkan hasil pengujian yang telah dilakukan, maka didapatkan kesimpulan sebagai berikut.

1. Ukuran area yang kecil $5 \times 5$ pada tahap ekstraksi ciri diagonal memberikan akurasi yang lebih tinggi dibanding ukuran area yang lebih besar $16 \times 16$ dengan rata-rata selisih sebesar $1.03 \%$ pada tahap validasi. Hal ini dikarenakan ukuran area yang lebih besar melibatkan lebih banyak piksel dengan nilai 0 sehingga nilai ciri yang didapatkan kecil.

2. Dengan jumlah fitur yang sama, kombinasi fitur diagonal \& rata-rata horizontal mendapatkan hasil yang lebih baik dibandingkan kombinasi fitur diagonal \& rata-rata vertikal dengan rata-rata selisih sebesar $0.28 \%$ pada tahap validasi. Karena bentuk angka pada umumnya nilai horizontal lebih bervariasi dibanding vertikal.

3. Kombinasi ukuran area $5 \times 5$ dan ciri diagonal + rata-rata secara horizontal memberikan akurasi tertinggi yaitu sebesar $91.525 \%$ pada tahap validasi. Serta parameter ANN-MLP yang sesuai pada ciri tersebut adalah 160 hidden neuron dan 0.07 pada nilai learning rate mendapatkan $92.375 \%$ pada tahap validasi.

4. Hasil pengujian terhadap parameter optimal yang didapat mendapatkan akurasi sebesar $92.30 \%$ pada dataset $\mathrm{C} 1$ dan $92.60 \%$ pada dataset MNIST.

\section{DAFTAR PUSTAKA}

[1] Gonzalez, R. C., Woods, R. W. (2002). Digital Image Processing. Education. https://doi.org/10.1049/ep.1978.0474

[2] Jindal, A., Dhir, R., \& Rani, R. (2012). Diagonal Features and SVM Classifier for Handwritten Gurumukhi Character Recognition. International Journal of Advanced Research in Computer Science and Software Engineering, 2(5), 505508 .

[3] LeCun, Y., Bottou, L., Bengio, Y., \& Haffner, P. (1998). Gradient-based learning applied to document recognition. Proceedings of the IEEE, 86(11), 2278-2323. https://doi.org/10.1109/5.726791

[4] Pradeep, J., Srinivasan, E., \& Himavathi, S. (2010). Diagonal Feature Extraction Based Handwritten Character System Using Neural Network. International Journal of Computer Applications, 8(9), 17-22. https://doi.org/10.5120/12361693

[5] Rajashekararadhya, S. V., \& Ranjan, P. V. (2009). Zone based Feature Extraction Algorithm for Handwritten Numeral Recognition of Kannada Script, (March), 6-7.

[6] Singh, G., \& Sachan, M. (2015). Multi-layer perceptron (MLP) neural network technique for offline handwritten Gurmukhi character recognition. 2014 IEEE International Conference on Computational Intelligence and Computing Research, IEEE ICCIC 2014, 1-5. https://doi.org/10.1109/ICCIC.2014.7238334

[7] Stehman, S. V. (1997). Selecting and interpreting measures of thematic classification accuracy. Remote Sensing of Environment, 62(1), 77-89. https://doi.org/10.1016/S0034-4257(97)00083-7 